\title{
Common fixed point theorems for weakly compatible mappings satisfying contractive conditions of integral type
}

\author{
Zeqing Liu', Yan Han', Shin Min Kang ${ }^{2^{*}}$ and Jeong Sheok Ume ${ }^{3}$
}

${ }^{*}$ Correspondence:

smkang@gnu.ac.kr

${ }^{2}$ Department of Mathematics and

RINS, Gyeongsang National

University, Jinju, 660-701, Korea

Full list of author information is

available at the end of the article

\begin{abstract}
Two common fixed theorems for weakly compatible mappings satisfying general contractive conditions of integral type in metric spaces are proved and an illustrative example is provided. The results obtained in this paper substantially extend and improve several previous results, particularly Theorem 2.1 of Branciari (Int. J. Math. Math. Sci. 29(9):531-536, 2002), Theorem 2 of Rhoades (Int. J. Math. Math. Sci. 2003(63):4007-4013, 2003) and Theorem 2 of Vijayaraju et al. (Int. J. Math. Math. Sci. 2005(15):2359-2364, 2005). A nontrivial example with uncountably many points is also provided to support the results presented herein.
\end{abstract}

MSC: $54 \mathrm{H} 25$

Keywords: contractive mappings of integral type; weakly compatible mappings; common fixed point

\section{Introduction and preliminaries}

In 2002, Branciari [1] introduced the notion of contractive mappings of integral type in metric spaces and proved the following fixed point theorem for the contractive mapping of integral type, which is a nice generalization of the Banach contraction principle.

Theorem $1.1([1])$ Let $(X, d)$ be a complete metric space, $c \in(0,1)$, and let $f: X \rightarrow X$ be a mapping such that

$$
\int_{0}^{d(f x, f y)} \varphi(s) d s \leq c \int^{d(x, y)} \varphi(s) d s, \quad \forall x, y \in X,
$$

where $\varphi:[0,+\infty) \rightarrow[0,+\infty)$ is a Lebesgue integrable mapping which is summable on each compact subset of $[0,+\infty)$ and such that for all $\varepsilon>0$,

$$
\int_{0}^{\varepsilon} \varphi(s) d s>0 .
$$

Then $f$ has a unique fixed point $a \in X$ such that for each $x \in X, \lim _{n \rightarrow \infty} f^{n} x=a$.

Afterward, the researchers [2-17] and others extended the result to more general contractive conditions of integral type. In particular, Rhoades [13] proved the following extension of Theorem 1.1 .

(92014 Liu et al.; licensee Springer. This is an Open Access article distributed under the terms of the Creative Commons Attribution License (http://creativecommons.org/licenses/by/2.0), which permits unrestricted use, distribution, and reproduction in any medium, provided the original work is properly cited. 
Theorem $1.2([13])$ Let $(X, d)$ be a complete metric space, $k \in[0,1), f: X \rightarrow X$ be a mapping such that

$$
\int_{0}^{d(f x, f y)} \varphi(s) d s \leq k \int^{m(x, y)} \varphi(s) d s, \quad \forall x, y \in X
$$

where

$$
m(x, y)=\max \left\{d(x, y), d(x, f x), d(y, f y), \frac{d(x, f y)+d(y, f x)}{2}\right\},
$$

$\varphi:[0,+\infty) \rightarrow[0,+\infty)$ is a Lebesgue integrable mapping which is summable on each compact subset of $[0,+\infty)$ and such that for all $\varepsilon>0$,

$$
\int_{0}^{\varepsilon} \varphi(s) d s>0
$$

Then $f$ has a unique fixed point $a \in X$ and, for each $x \in X, \lim _{n \rightarrow \infty} f^{n} x=a$.

Vijayaraju et al. [17] extended further Theorems 1.1 and 1.2 from a single mapping to a pair of mappings. Using a rational expression for a contractive condition of integral type, Vetro [16] extended also Theorem 1.1 and proved the following common fixed point theorem for weakly compatible mappings.

Theorem 1.3 ([16]) Let $(X, d)$ be a metric space and let $A, B, S$ and $T$ be self-mappings of $X$ with $S(X) \subseteq B(X)$ and $T(X) \subseteq A(X)$ such that

$$
\int_{0}^{d(S x, T y)} \varphi(s) d s \leq \alpha \int_{0}^{m(x, y)} \varphi(s) d s+\beta \int_{0}^{M(x, y)} \varphi(s) d s, \quad \forall x, y \in X,
$$

where

$$
\begin{aligned}
& m(x, y)=d(B y, T y) \frac{1+d(A x, S x)}{1+d(A x, B y)}, \\
& M(x, y)=\max \{d(A x, B y), d(A x, S x), d(B y, T y)\},
\end{aligned}
$$

$\alpha>0, \beta>0, \alpha+\beta<1$ and $\varphi:[0,+\infty) \rightarrow[0,+\infty)$ is a Lebesgue integrable mapping on each compact subset of $[0,+\infty)$ and such that for all $\varepsilon>0$,

$$
\int_{0}^{\varepsilon} \varphi(s) d s>0
$$

Suppose that one of $A(X), B(X), S(X)$ and $T(X)$ is a complete subset of $X$ and the pairs $\{A, S\}$ and $\{B, T\}$ are weakly compatible. Then $A, B, S$ and $T$ have a unique common fixed point in $X$.

Motivated and inspired by the results in [1-17], in this paper we introduce more general contractive mappings of integral type, which include the contractive mappings of integral type in $[1,4,13,16,17]$ as special cases, and we establish the existence and uniqueness 
of common fixed points for these contractive mappings of integral type with weak compatibility. Our results extend, improve and unify the corresponding results in $[1,4,13,16$, 17]. A nontrivial example with uncountably many points is also provided to support the results presented herein.

Throughout this paper, we assume that $\mathbb{R}^{+}=[0,+\infty), \mathbb{R}=(-\infty,+\infty), \mathbb{N}_{0}=\{0\} \cup \mathbb{N}$, where $\mathbb{N}$ denotes the set of all positive integers and

$\Phi=\left\{\varphi: \varphi: \mathbb{R}^{+} \rightarrow \mathbb{R}^{+}\right.$satisfies that $\varphi$ is Lebesgue integrable, summable on each compact subset of $\mathbb{R}^{+}$and $\int_{0}^{\varepsilon} \varphi(t) d t>0$ for each $\left.\varepsilon>0\right\}$,

$\Psi=\left\{\psi: \psi: \mathbb{R}^{+} \rightarrow \mathbb{R}^{+}\right.$is upper semi-continuous on $\mathbb{R}^{+} \backslash\{0\}, \psi(0)=0$ and $\psi(t)<t$ for each $t>0\}$,

$\Psi_{1}=\left\{\psi: \psi: \mathbb{R}^{+} \rightarrow \mathbb{R}^{+}\right.$is nondecreasing on $\mathbb{R}^{+}, \psi(t)<t$ and $\sum_{n=1}^{\infty} \psi^{n}(t)<+\infty$ for each $t>0\}$.

Recall that a pair of self-mappings $f$ and $g$ in a metric space $(X, d)$ are said to be weakly compatible if for all $t \in X$ the equality $f t=g t$ implies $f g t=g f t$.

Lemma 1.4 ([9]) Let $\varphi \in \Phi$ and $\left\{r_{n}\right\}_{n \in \mathbb{N}}$ be a nonnegative sequence. Then

$$
\lim _{n \rightarrow \infty} \int_{0}^{r_{n}} \varphi(t) d t=0
$$

if and only if $\lim _{n \rightarrow \infty} r_{n}=0$.

\section{Common fixed point theorems}

Now we show two common fixed point theorems for four contractive mappings of integral type in metric spaces.

Theorem 2.1 Let $A, B$, $S$ and $T$ be self-mappings of a metric space $(X, d)$ such that

(C1) $S(X) \subseteq B(X)$ and $T(X) \subseteq A(X)$;

(C2) the pairs $\{A, S\}$ and $\{B, T\}$ are weakly compatible;

(C3) one of $A(X), B(X), S(X)$ and $T(X)$ is a complete subset of $X$ and

$$
\int_{0}^{d(S x, T y)} \varphi(t) d t \leq \psi\left(\max \left\{\int_{0}^{m_{i}(x, y)} \varphi(t) d t: 1 \leq i \leq 4\right\}\right), \quad \forall x, y \in X
$$

where $(\psi, \varphi)$ is in $\Psi \times \Phi$ and

$$
\begin{aligned}
m_{1}(x, y)= & d(B y, T y) \frac{1+d(A x, S x)}{1+d(A x, B y)}, \\
m_{2}(x, y)= & d(A x, S x) \frac{1+d(B y, T y)}{1+d(A x, B y)}, \\
m_{3}(x, y)= & \frac{d(S x, B y) d(T y, A x)}{1+d(A x, B y)}, \\
m_{4}(x, y)= & \max \{d(A x, B y), d(A x, S x), d(B y, T y), \\
& \left.\frac{1}{2}[d(S x, B y)+d(T y, A x)]\right\} .
\end{aligned}
$$

Then $A, B, S$ and $T$ have a unique common fixed point in $X$. 
Proof Let $x_{0} \in X$. It follows from (C1) that there exist two sequences $\left\{y_{n}\right\}_{n \in \mathbb{N}}$ and $\left\{x_{n}\right\}_{n \in \mathbb{N}_{0}}$ in $X$ satisfying

$$
y_{2 n+1}=S x_{2 n}=B x_{2 n+1} \quad \text { and } \quad y_{2 n+2}=T x_{2 n+1}=A x_{2 n+2}, \quad \forall n \in \mathbb{N}_{0} .
$$

Put $d_{n}=d\left(y_{n}, y_{n+1}\right)$ for each $n \in \mathbb{N}$.

Firstly we show that $A, B, S$ and $T$ have at most a common fixed point in $X$. Suppose that $u$ and $v$ are two different common fixed points of $A, B, S$ and $T$ in $X$. It follows from (2.1), (2.2) and $(\psi, \varphi) \in \Psi \times \Phi$ that

$$
\begin{aligned}
& m_{1}(u, v)=d(B v, T v) \frac{1+d(A u, S u)}{1+d(A u, B v)}=0 \\
& m_{2}(u, v)=d(A u, S u) \frac{1+d(B v, T v)}{1+d(A u, B v)}=0 \\
& m_{3}(u, v)=\frac{d(S u, B v) d(T v, A u)}{1+d(A u, B v)}=\frac{d^{2}(u, v)}{1+d(u, v)}, \\
& m_{4}(u, v)=\max \left\{d(A u, B v), d(A u, S u), d(B v, T v), \frac{1}{2}[d(S u, B v)+d(T v, A u)]\right\}=d(u, v)
\end{aligned}
$$

and

$$
\begin{aligned}
\int_{0}^{d(u, v)} \varphi(t) d t & =\int_{0}^{d(S u, T v)} \varphi(t) d t \\
& \leq \psi\left(\max \left\{\int_{0}^{m_{i}(u, v)} \varphi(t) d t: 1 \leq i \leq 4\right\}\right) \\
& =\psi\left(\max \left\{0,0, \int_{0}^{\frac{d^{2}(u, v)}{1+d(u, v)}} \varphi(t) d t, \int_{0}^{d(u, v)} \varphi(t) d t\right\}\right) \\
& =\psi\left(\int_{0}^{d(u, v)} \varphi(t) d t\right)<\int_{0}^{d(u, v)} \varphi(t) d t
\end{aligned}
$$

which is a contradiction. Hence $A, B, S$ and $T$ have at most a common fixed point in $X$.

Secondly we show that $A, B, S$ and $T$ have a common fixed point $A a \in X$ if there exist $a, b \in X$ satisfying

$$
A a=S a=B b=T b .
$$

Assume that (2.4) holds for some $a, b \in X$. Put $c=A a$. Note that (C2) implies that

$$
S c=S A a=A S a=A c \quad \text { and } \quad B c=B T b=T B b=T c .
$$

Suppose that $c \neq T c$. In view of (2.1), (2.2), (2.4), (2.5) and $(\psi, \varphi) \in \Psi \times \Phi$, we infer that

$$
\begin{aligned}
& m_{1}(a, c)=d(B c, T c) \frac{1+d(A a, S a)}{1+d(A a, B c)}=0 \\
& m_{2}(a, c)=d(A a, S a) \frac{1+d(B c, T c)}{1+d(A a, B c)}=0
\end{aligned}
$$




$$
\begin{aligned}
m_{3}(a, c) & =\frac{d(S a, B c) d(T c, A a)}{1+d(A a, B c)}=\frac{d(c, B c) d(T c, c)}{1+d(c, B c)}=\frac{d^{2}(c, T c)}{1+d(c, T c)} \\
m_{4}(a, c) & =\max \left\{d(A a, B c), d(A a, S a), d(B c, T c), \frac{1}{2}[d(S a, B c)+d(T c, A a)]\right\} \\
& =\max \left\{d(c, B c), 0,0, \frac{1}{2}[d(c, B c)+d(T c, c)]\right\}=d(c, T c)
\end{aligned}
$$

and

$$
\begin{aligned}
\int_{0}^{d(c, T c)} \varphi(t) d t & =\int_{0}^{d(S a, T c)} \varphi(t) d t \\
& \leq \psi\left(\max \left\{\int_{0}^{m_{i}(a, c)} \varphi(t) d t: 1 \leq i \leq 4\right\}\right) \\
& =\psi\left(\max \left\{0,0, \int_{0}^{\frac{d^{2}(c, T c)}{1+d(c, T c)}} \varphi(t) d t, \int_{0}^{d(c, T c)} \varphi(t) d t\right\}\right) \\
& =\psi\left(\int_{0}^{d(c, T c)} \varphi(t) d t\right)<\int_{0}^{d(c, T c)} \varphi(t) d t,
\end{aligned}
$$

which is impossible. Consequently, $c=T c=B c$. Similarly we conclude that $c=A c=S c$. That is, $c$ is a common fixed point of $A, B, S$ and $T$.

Thirdly we show that (2.4) holds for some $a, b \in X$. In order to prove (2.4), we have to consider three possible cases as follows.

Case 1. There exists $n_{0} \in \mathbb{N}$ satisfying $d_{2 n_{0}}=0$. We claim that $d_{2 n_{0}+1}=0$. Otherwise $d_{2 n_{0}+1}>0$. Using (2.1)-(2.3) and $(\psi, \varphi) \in \Psi \times \Phi$, we deduce that

$$
\begin{aligned}
m_{1}\left(x_{2 n_{0}}, x_{2 n_{0}+1}\right)= & d\left(B x_{2 n_{0}+1}, T x_{2 n_{0}+1}\right) \frac{1+d\left(A x_{2 n_{0}}, S x_{2 n_{0}}\right)}{1+d\left(A x_{2 n_{0}}, B x_{2 n_{0}+1}\right)} \\
= & d\left(y_{2 n_{0}+1}, y_{2 n_{0}+2}\right) \frac{1+d\left(y_{2 n_{0}}, y_{2 n_{0}+1}\right)}{1+d\left(y_{2 n_{0}}, y_{2 n_{0}+1}\right)}=d_{2 n_{0}+1}, \\
m_{2}\left(x_{2 n_{0}}, x_{2 n_{0}+1}\right)= & d\left(A x_{2 n_{0}}, S x_{2 n_{0}}\right) \frac{1+d\left(B x_{2 n_{0}+1}, T x_{2 n_{0}+1}\right)}{1+d\left(A x_{2 n_{0}}, B x_{2 n_{0}+1}\right)} \\
= & d\left(y_{2 n_{0}}, y_{2 n_{0}+1}\right) \frac{1+d\left(y_{2 n_{0}+1}, y_{2 n_{0}+2}\right)}{1+d\left(y_{2 n_{0}}, y_{2 n_{0}+1}\right)}=0, \\
m_{3}\left(x_{2 n_{0}}, x_{2 n_{0}+1}\right)= & \frac{d\left(S x_{2 n_{0}}, B x_{2 n_{0}+1}\right) d\left(T x_{2 n_{0}+1}, A x_{2 n_{0}}\right)}{1+d\left(A x_{2 n_{0}}, B x_{2 n_{0}+1}\right)} \\
= & \frac{d\left(y_{2 n_{0}+1}, y_{2 n_{0}+1}\right) d\left(y_{2 n_{0}+2}, y_{2 n_{0}}\right)}{1+d\left(y_{2 n_{0}}, y_{2 n_{0}+1}\right)}=0, \\
m_{4}\left(x_{2 n_{0}}, x_{2 n_{0}+1}\right)= & \max \left\{d\left(A x_{2 n_{0}}, B x_{2 n_{0}+1}\right), d\left(A x_{2 n_{0}}, S x_{2 n_{0}}\right), d\left(B x_{2 n_{0}+1}, T x_{2 n_{0}+1}\right),\right. \\
& \left.\frac{1}{2}\left[d\left(S x_{2 n_{0}}, B x_{2 n_{0}+1}\right)+d\left(T x_{2 n_{0}+1}, A x_{2 n_{0}}\right)\right]\right\} \\
= & \max \left\{d\left(y_{2 n_{0}}, y_{2 n_{0}+1}\right), d\left(y_{2 n_{0}}, y_{2 n_{0}+1}\right), d\left(y_{2 n_{0}+1}, y_{2 n_{0}+2}\right),\right. \\
& \left.\frac{1}{2}\left[d\left(y_{2 n_{0}+1}, y_{2 n_{0}+1}\right)+d\left(y_{2 n_{0}+2}, y_{2 n_{0}}\right)\right]\right\}=\max \left\{d_{2 n_{0}}, d_{2 n_{0}+1}\right\}=d_{2 n_{0}+1}
\end{aligned}
$$


and

$$
\begin{aligned}
& \int_{0}^{d_{2 n_{0}+1}} \varphi(t) d t=\int_{0}^{d\left(y_{2 n_{0}+1}, y_{2 n_{0}+2}\right)} \varphi(t) d t=\int_{0}^{d\left(S x_{2 n_{0}}, T x_{2 n_{0}+1}\right)} \varphi(t) d t \\
& \leq \psi\left(\max \left\{\int_{0}^{m_{i}\left(x_{2 n_{0}}, x_{2 n_{0}+1}\right)} \varphi(t) d t: 1 \leq i \leq 4\right\}\right) \\
& =\psi\left(\max \left\{\int_{0}^{d_{2 n_{0}+1}} \varphi(t) d t, 0,0, \int_{0}^{d_{2 n_{0}+1}} \varphi(t) d t\right\}\right) \\
& <\int_{0}^{d_{2 n_{0}+1}} \varphi(t) d t
\end{aligned}
$$

which is a contradiction. Hence $d_{2 n_{0}+1}=0$. It follows that

$$
A x_{2 n_{0}}=y_{2 n_{0}}=y_{2 n_{0}+1}=S x_{2 n_{0}} \quad \text { and } \quad B x_{2 n_{0}+1}=y_{2 n_{0}+1}=y_{2 n_{0}+2}=T x_{2 n_{0}+1} \text {. }
$$

Put $a=x_{2 n_{0}}$ and $b=x_{2 n_{0}+1}$. It is easy to see that (2.4) holds and $y_{2 n_{0}}$ is a common fixed point of $A, B, S$ and $T$.

Case 2. There exists $n_{0} \in \mathbb{N}$ satisfying $d_{2 n_{0}-1}=0$. As in the proof of Case 1 , we infer similarly that (2.4) holds for $a=x_{2 n_{0}}$ and $b=x_{2 n_{0}-1}$, and $y_{2 n_{0}-1}$ is a common fixed point of $A, B, S$ and $T$.

Case 3. $y_{n} \neq y_{n+1}$ for all $n \in \mathbb{N}$. Now we claim that $d_{2 n} \leq d_{2 n-1}$ for all $n \in \mathbb{N}$. Suppose that $d_{2 n}>d_{2 n-1}$ for some $n \in \mathbb{N}$. By virtue of (2.1), (2.2) and $(\psi, \varphi) \in \Psi \times \Phi$, we arrive at

$$
\begin{aligned}
m_{1}\left(x_{2 n}, x_{2 n-1}\right)= & d\left(B x_{2 n-1}, T x_{2 n-1}\right) \frac{1+d\left(A x_{2 n}, S x_{2 n}\right)}{1+d\left(A x_{2 n}, B x_{2 n-1}\right)} \\
= & d\left(y_{2 n-1}, y_{2 n}\right) \frac{1+d\left(y_{2 n}, y_{2 n+1}\right)}{1+d\left(y_{2 n}, y_{2 n-1}\right)}=d_{2 n-1} \frac{1+d_{2 n}}{1+d_{2 n-1}}<d_{2 n} \\
m_{2}\left(x_{2 n}, x_{2 n-1}\right)= & d\left(A x_{2 n}, S x_{2 n}\right) \frac{1+d\left(B x_{2 n-1}, T x_{2 n-1}\right)}{1+d\left(A x_{2 n}, B x_{2 n-1}\right)} \\
= & d\left(y_{2 n}, y_{2 n+1}\right) \frac{1+d\left(y_{2 n-1}, y_{2 n}\right)}{1+d\left(y_{2 n}, y_{2 n-1}\right)}=d_{2 n}, \\
m_{3}\left(x_{2 n}, x_{2 n-1}\right)= & \frac{d\left(S x_{2 n}, B x_{2 n-1}\right) d\left(T x_{2 n-1}, A x_{2 n}\right)}{1+d\left(A x_{2 n}, B x_{2 n-1}\right)} \\
= & \frac{d\left(y_{2 n+1}, y_{2 n-1}\right) d\left(y_{2 n}, y_{2 n}\right)}{1+d\left(y_{2 n}, y_{2 n-1}\right)}=0, \\
m_{4}\left(x_{2 n}, x_{2 n-1}\right)= & \max \left\{d\left(A x_{2 n}, B x_{2 n-1}\right), d\left(A x_{2 n}, S x_{2 n}\right), d\left(B x_{2 n-1}, T x_{2 n-1}\right),\right. \\
& \left.\frac{1}{2}\left[d\left(S x_{2 n}, B x_{2 n-1}\right)+d\left(T x_{2 n-1}, A x_{2 n}\right)\right]\right\} \\
& \left.\frac{1}{2}\left[d\left(y_{2 n+1}, y_{2 n-1}\right)+d\left(y_{2 n}, y_{2 n}\right)\right]\right\} \\
= & \max \left\{d_{2 n-1}, d_{2 n}\right\}=d_{2 n} \\
& \max \left\{d\left(y_{2 n}, y_{2 n-1}\right), d\left(y_{2 n}, y_{2 n+1}\right), d\left(y_{2 n-1}, y_{2 n}\right)\right.
\end{aligned}
$$


and

$$
\begin{aligned}
\int_{0}^{d_{2 n}} \varphi(t) d t & =\int_{0}^{d\left(y_{2 n+1}, y_{2 n}\right)} \varphi(t) d t=\int_{0}^{d\left(S x_{2 n}, T x_{2 n-1}\right)} \varphi(t) d t \\
& \leq \psi\left(\max \left\{\int_{0}^{m_{i}\left(x_{2 n}, x_{2 n-1}\right)} \varphi(t) d t: 1 \leq i \leq 4\right\}\right) \\
& =\psi\left(\max \left\{\int_{0}^{d_{2 n-1} \frac{1+d_{2 n}}{1+d_{2 n-1}}} \varphi(t) d t, \int_{0}^{d_{2 n}} \varphi(t) d t, 0, \int_{0}^{d_{2 n}} \varphi(t) d t\right\}\right) \\
& =\psi\left(\int_{0}^{d_{2 n}} \varphi(t) d t\right)<\int_{0}^{d_{2 n}} \varphi(t) d t,
\end{aligned}
$$

which is absurd. Hence $d_{2 n} \leq d_{2 n-1}$ for each $n \in \mathbb{N}$. As in the proofs of (2.6) and (2.7), we infer similarly that $d_{2 n+1} \leq d_{2 n}$ for all $n \in \mathbb{N}$. Consequently, $\left\{d_{n}\right\}_{n \in \mathbb{N}}$ is a nonincreasing positive sequence, which means that there exists a constant $r \geq 0$ with

$$
\lim _{n \rightarrow \infty} d_{n}=r
$$

Suppose that $r>0$. Making use of (2.1), (2.2), (2.6), (2.8) and $(\psi, \varphi) \in \Psi \times \Phi$ and Lemma 1.4, we get that

$$
\begin{aligned}
\int_{0}^{r} \varphi(t) d t & =\limsup _{n \rightarrow \infty} \int_{0}^{d_{2 n}} \varphi(t) d t=\limsup _{n \rightarrow \infty} \int_{0}^{d\left(y_{2 n+1}, y_{2 n}\right)} \varphi(t) d t \\
& =\limsup _{n \rightarrow \infty} \int_{0}^{d\left(S x_{2 n}, T x_{2 n-1}\right)} \varphi(t) d t \\
\leq & \limsup _{n \rightarrow \infty} \psi\left(\max \left\{\int_{0}^{m_{i}\left(x_{2 n}, x_{2 n-1}\right)} \varphi(t) d t: 1 \leq i \leq 4\right\}\right) \\
\leq & \psi\left(\operatorname { l i m s u p } _ { n \rightarrow \infty } \operatorname { m a x } \left\{\int_{0}^{d_{2 n-1} \frac{1+d_{2 n}}{1+d_{2 n-1}} \varphi(t) d t, \int_{0}^{d_{2 n}} \varphi(t) d t, 0}\right.\right. \\
& \left.\left.\int_{0}^{\max \left\{d_{2 n-1}, d_{2 n}\right\}} \varphi(t) d t\right\}\right) \\
= & \psi\left(\max _{0}\left\{\int_{0}^{r} \varphi(t) d t, \int_{0}^{r} \varphi(t) d t, 0, \int_{0}^{r} \varphi(t) d t\right\}\right) \\
= & \psi\left(\int_{0}^{r} \varphi(t) d t\right)<\int_{0}^{r} \varphi(t) d t,
\end{aligned}
$$

which is a contradiction. Hence $r=0$. That is,

$$
\lim _{n \rightarrow \infty} d_{n}=0
$$

In order to prove that $\left\{y_{n}\right\}_{n \in \mathbb{N}}$ is a Cauchy sequence, by (2.9) we need only to prove that $\left\{y_{2 n}\right\}_{n \in \mathbb{N}}$ is a Cauchy sequence. Suppose that $\left\{y_{2 n}\right\}_{n \in \mathbb{N}}$ is not a Cauchy sequence. It follows that there exists $\varepsilon>0$ such that for each even integer $2 k$ there are even integers $2 m(k)$, $2 n(k)$ with $2 m(k)>2 n(k)>2 k$ and

$$
d\left(y_{2 n(k)}, y_{2 m(k)}\right) \geq \varepsilon .
$$


For every even integer $2 k$, let $2 m(k)$ be the least even integer exceeding $2 n(k)$ satisfying (2.10). It follows that

$$
d\left(y_{2 n(k)}, y_{2 m(k)-2}\right)<\varepsilon, \quad \forall k \in \mathbb{N} .
$$

Note that

$$
\begin{aligned}
& d\left(y_{2 n(k)}, y_{2 m(k)}\right) \leq d\left(y_{2 n(k)}, y_{2 m(k)-2}\right)+d_{2 m(k)-2}+d_{2 m(k)-1}, \quad \forall k \in \mathbb{N} ; \\
& \left|d\left(y_{2 n(k)+1}, y_{2 m(k)}\right)-d\left(y_{2 n(k)}, y_{2 m(k)}\right)\right| \leq d_{2 n(k)}, \quad \forall k \in \mathbb{N} ; \\
& \left|d\left(y_{2 n(k)}, y_{2 m(k)-1}\right)-d\left(y_{2 n(k)}, y_{2 m(k)}\right)\right| \leq d_{2 m(k)-1}, \quad \forall k \in \mathbb{N} ; \\
& \left|d\left(y_{2 n(k)+1}, y_{2 m(k)-1}\right)-d\left(y_{2 n(k)+1}, y_{2 m(k)}\right)\right| \leq d_{2 m(k)-1}, \quad \forall k \in \mathbb{N} .
\end{aligned}
$$

In terms of (2.9)-(2.12), we know that

$$
\begin{aligned}
\varepsilon & =\lim _{k \rightarrow \infty} d\left(y_{2 n(k)}, y_{2 m(k)}\right)=\lim _{k \rightarrow \infty} d\left(y_{2 n(k)+1}, y_{2 m(k)}\right) \\
& =\lim _{k \rightarrow \infty} d\left(y_{2 n(k)}, y_{2 m(k)-1}\right)=\lim _{k \rightarrow \infty} d\left(y_{2 n(k)+1}, y_{2 m(k)-1}\right) .
\end{aligned}
$$

In light of (2.1), (2.2), (2.9), (2.13), $(\psi, \varphi) \in \Psi \times \Phi$ and Lemma 1.4, we deduce that

$$
\begin{aligned}
& m_{1}\left(x_{2 n(k)}, x_{2 m(k)-1}\right) \\
& =d\left(B x_{2 m(k)-1}, T x_{2 m(k)-1}\right) \frac{1+d\left(A x_{2 n(k)}, S x_{2 n(k)}\right)}{1+d\left(A x_{2 n(k)}, B x_{2 m(k)-1}\right)} \\
& =d\left(y_{2 m(k)-1}, y_{2 m(k)}\right) \frac{1+d\left(y_{2 n(k)}, y_{2 n(k)+1}\right)}{1+d\left(y_{2 n(k)}, y_{2 m(k)-1}\right)} \rightarrow 0 \quad \text { as } k \rightarrow \infty, \\
& m_{2}\left(x_{2 n(k)}, x_{2 m(k)-1}\right) \\
& =d\left(A x_{2 n(k)}, S x_{2 n(k)}\right) \frac{1+d\left(B x_{2 m(k)-1}, T x_{2 m(k)-1}\right)}{1+d\left(A x_{2 n(k)}, B x_{2 m(k)-1}\right)} \\
& =d\left(y_{2 n(k)}, y_{2 n(k)+1}\right) \frac{1+d\left(y_{2 m(k)-1}, y_{2 m(k)}\right)}{1+d\left(y_{2 n(k)}, y_{2 m(k)-1}\right)} \rightarrow 0 \quad \text { as } k \rightarrow \infty \text {, } \\
& m_{3}\left(x_{2 n(k)}, x_{2 m(k)-1}\right) \\
& =\frac{d\left(S x_{2 n(k)}, B x_{2 m(k)-1}\right) d\left(T x_{2 m(k)-1}, A x_{2 n(k)}\right)}{1+d\left(A x_{2 n(k)}, B x_{2 m(k)-1}\right)} \\
& =\frac{d\left(y_{2 n(k)+1}, y_{2 m(k)-1}\right) d\left(y_{2 m(k)}, y_{2 n(k)}\right)}{1+d\left(y_{2 n(k)}, y_{2 m(k)-1}\right)} \rightarrow \frac{\varepsilon^{2}}{1+\varepsilon} \quad \text { as } k \rightarrow \infty, \\
& m_{4}\left(x_{2 n(k)}, x_{2 m(k)-1}\right) \\
& =\max \left\{d\left(A x_{2 n(k)}, B x_{2 m(k)-1}\right), d\left(A x_{2 n(k)}, S x_{2 n(k)}\right), d\left(B x_{2 m(k)-1}, T x_{2 m(k)-1}\right),\right. \\
& \left.\frac{1}{2}\left[d\left(S x_{2 n(k)}, B x_{2 m(k)-1}\right)+d\left(T x_{2 m(k)-1}, A x_{2 n(k)}\right)\right]\right\} \\
& =\max \left\{d\left(y_{2 n(k)}, y_{2 m(k)-1}\right), d\left(y_{2 n(k)}, y_{2 n(k)+1}\right), d\left(y_{2 m(k)-1}, y_{2 m(k)}\right),\right. \\
& \left.\frac{1}{2}\left[d\left(y_{2 n(k)+1}, y_{2 m(k)-1}\right)+d\left(y_{2 m(k)}, y_{2 n(k)}\right)\right]\right\} \rightarrow \varepsilon \quad \text { as } k \rightarrow \infty
\end{aligned}
$$


and

$$
\begin{aligned}
\int_{0}^{\varepsilon} \varphi(t) d t & =\limsup _{k \rightarrow \infty} \int_{0}^{d\left(y_{2 n(k)+1}, y_{2 m(k)}\right)} \varphi(t) d t=\limsup _{k \rightarrow \infty} \int_{0}^{d\left(S x_{2 n(k)}, T x_{2 m(k)-1}\right)} \varphi(t) d t \\
& \leq \limsup _{k \rightarrow \infty} \psi\left(\max \left\{\int_{0}^{m_{i}\left(x_{2 n(k)}, x_{2 m(k)-1}\right)} \varphi(t) d t: 1 \leq i \leq 4\right\}\right) \\
& \leq \psi\left(\limsup _{k \rightarrow \infty} \max \left\{\int_{0}^{m_{i}\left(x_{2 n(k)}, x_{2 m(k)-1}\right)} \varphi(t) d t: 1 \leq i \leq 4\right\}\right) \\
& =\psi\left(\max \left\{0,0, \int_{0}^{\frac{\varepsilon^{2}}{1+\varepsilon}} \varphi(t) d t, \int_{0}^{\varepsilon} \varphi(t) d t\right\}\right) \\
& =\psi\left(\int_{0}^{\varepsilon} \varphi(t) d t\right)<\int_{0}^{\varepsilon} \varphi(t) d t,
\end{aligned}
$$

which is a contradiction. Therefore $\left\{y_{n}\right\}_{n \in \mathbb{N}}$ is a Cauchy sequence.

Assume that $A(X)$ is complete. Notice that $\left\{y_{2 n}\right\}_{n \in \mathbb{N}} \subseteq A(X)$, which implies that $\left\{y_{2 n}\right\}_{n \in \mathbb{N}}$ converges to a point $c \in A(X)$. Obviously $\lim _{n \rightarrow \infty} y_{n}=c$. Put $a \in A^{-1} c$. It follows that $A a=c$. Suppose that $S a \neq c$. In view of (2.1)-(2.3), $(\psi, \varphi) \in \Psi \times \Phi$, Lemma 1.4 and $\lim _{n \rightarrow \infty} y_{n}=c$, we infer that

$$
\begin{aligned}
m_{1}\left(a, x_{2 n-1}\right)= & d\left(B x_{2 n-1}, T x_{2 n-1}\right) \frac{1+d(A a, S a)}{1+d\left(A a, B x_{2 n-1}\right)} \\
= & d\left(y_{2 n-1}, y_{2 n}\right) \frac{1+d(c, S a)}{1+d\left(c, y_{2 n-1}\right)} \rightarrow 0 \quad \text { as } n \rightarrow \infty, \\
m_{2}\left(a, x_{2 n-1}\right)= & d(A a, S a) \frac{1+d\left(B x_{2 n-1}, T x_{2 n-1}\right)}{1+d\left(A a, B x_{2 n-1}\right)} \\
= & d(c, S a) \frac{1+d\left(y_{2 n-1}, y_{2 n}\right)}{1+d\left(c, y_{2 n-1}\right)} \rightarrow d(c, S a) \quad \text { as } n \rightarrow \infty, \\
m_{3}\left(a, x_{2 n-1}\right)= & \frac{d\left(S a, B x_{2 n-1}\right) d\left(T x_{2 n-1}, A a\right)}{1+d\left(A a, B x_{2 n-1}\right)} \\
= & \frac{d\left(S a, y_{2 n-1}\right) d\left(y_{2 n}, c\right)}{1+d\left(c, y_{2 n-1}\right)} \rightarrow 0 \quad \text { as } n \rightarrow \infty, \\
m_{4}\left(a, x_{2 n-1}\right)= & \max \left\{d\left(A a, B x_{2 n-1}\right), d(A a, S a), d\left(B x_{2 n-1}, T x_{2 n-1}\right),\right. \\
& \left.\frac{1}{2}\left[d\left(S a, B x_{2 n-1}\right)+d\left(T x_{2 n-1}, A a\right)\right]\right\} \\
= & \max \left\{d\left(c, y_{2 n-1}\right), d(c, S a), d\left(y_{2 n-1}, y_{2 n}\right),\right. \\
& \left.\frac{1}{2}\left[d\left(S a, y_{2 n-1}\right)+d\left(y_{2 n}, c\right)\right]\right\} \rightarrow d(c, S a) \quad \text { as } n \rightarrow \infty
\end{aligned}
$$

and

$$
\begin{aligned}
\int_{0}^{d(S a, c)} \varphi(t) d t & =\limsup _{n \rightarrow \infty} \int_{0}^{d\left(S a, y_{2 n}\right)} \varphi(t) d t=\limsup _{n \rightarrow \infty} \int_{0}^{d\left(S a, T x_{2 n-1}\right)} \varphi(t) d t \\
& \leq \limsup _{n \rightarrow \infty} \psi\left(\max \left\{\int_{0}^{m_{i}\left(a, x_{2 n-1}\right)} \varphi(t) d t: 1 \leq i \leq 4\right\}\right)
\end{aligned}
$$




$$
\begin{aligned}
& \leq \psi\left(\limsup _{n \rightarrow \infty} \max \left\{\int_{0}^{m_{i}\left(a, x_{2 n-1}\right)} \varphi(t) d t: 1 \leq i \leq 4\right\}\right) \\
& =\psi\left(\max \left\{0, \int_{0}^{d(c, S a)} \varphi(t) d t, 0, \int_{0}^{d(c, S a)} \varphi(t) d t\right\}\right) \\
& =\psi\left(\int_{0}^{d(c, S a)} \varphi(t) d t\right)<\int_{0}^{d(c, S a)} \varphi(t) d t,
\end{aligned}
$$

which is a contradiction. Therefore, $S a=c$, which together with (C1) means that $c \in B(X)$. Put $b \in B^{-1} c$, that is, $B b=c$. Suppose that $c \neq T b$. By means of (2.1), (2.2) and $(\psi, \varphi) \in$ $\Psi \times \Phi$, we get that

$$
\begin{aligned}
m_{1}(a, b) & =d(B b, T b) \frac{1+d(A a, S a)}{1+d(A a, B b)}=d(c, T b), \\
m_{2}(a, b) & =d(A a, S a) \frac{1+d(B b, T b)}{1+d(A a, B b)}=0, \\
m_{3}(a, b) & =\frac{d(S a, B b) d(T b, A a)}{1+d(A a, B b)}=0, \\
m_{4}(a, b) & =\max \left\{d(A a, B b), d(A a, S a), d(B b, T b), \frac{1}{2}[d(S a, B b)+d(T b, A a)]\right\} \\
& =\max \left\{0,0, d(c, T b), \frac{1}{2}[0+d(T b, c)]\right\} \\
& =d(c, T b)
\end{aligned}
$$

and

$$
\begin{aligned}
\int_{0}^{d(c, T b)} \varphi(t) d t & =\int_{0}^{d(S a, T b)} \varphi(t) d t \leq \psi\left(\max \left\{\int_{0}^{m_{i}(a, b)} \varphi(t) d t: 1 \leq i \leq 4\right\}\right) \\
& =\psi\left(\max \left\{\int_{0}^{d(c, T b)} \varphi(t) d t, 0,0, \int_{0}^{d(c, T b)} \varphi(t) d t\right\}\right) \\
& =\psi\left(\int_{0}^{d(c, T b)} \varphi(t) d t\right)<\int_{0}^{d(c, T b)} \varphi(t) d t,
\end{aligned}
$$

which is impossible. That is, $c=T b$. Hence (2.4) holds.

Assume that $T(X)$ is complete. Notice that $\left\{y_{2 n}\right\}_{n \in \mathbb{N}} \subseteq T(X)$, which implies that $\left\{y_{2 n}\right\}_{n \in \mathbb{N}}$ converges to a point $c \in T(X)$. Obviously $\lim _{n \rightarrow \infty} y_{n}=c$. Put $b_{1} \in T^{-1} c$. It follows that $T b_{1}=c$. Observe that $T(X) \subseteq A(X)$, which implies that there exists $a \in X$ with $A a=T b_{1}=c$. As in the proof of completeness of $A(X)$, we infer that (2.4) holds. Similarly we conclude that (2.4) holds if one of $B(X)$ and $S(X)$ is complete. This completes the proof.

As in the proof of Theorem 2.1 we have the following result and omit its proof.

Theorem 2.2 Let $A, B, S$ and $T$ be self-mappings of a metric space $(X, d)$ satisfying $(C 1)$ (C3) and

$$
\int_{0}^{d(S x, T y)} \varphi(t) d t \leq \psi\left(\int_{0}^{m_{4}(x, y)} \varphi(t) d t\right), \quad \forall x, y \in X
$$


where $(\psi, \varphi)$ is in $\Psi \times \Phi$ and $m_{4}$ is defined by (2.2). Then $A, B$, $S$ and $T$ have a unique common fixed point in $X$.

Remark 2.3 Theorems 2.1 and 2.2 extend, improve and unify Theorem 2.1 in [1, 4], Theorem 2 in $[13,16,17]$ and Corollary 3 in [17]. The following example reveals that Theorem 2.2 is both an indeed generalization of Theorem 2.1 in [1], Theorem 2 in [13, 17] and Corollary 3 in [17], and different from Theorems 3.1-3.3 in [9].

Example 2.4 Let $X=\mathbb{R}$ be endowed with the Euclidean metric $d(x, y)=|x-y|$ for all $x, y \in X$. Let $S, T: X \rightarrow X$ be defined by

$$
S x=\left\{\begin{array}{ll}
2, & \forall x \in X-\{1\}, \\
\frac{3}{2}, & x=1,
\end{array} \quad T x=2, \quad \forall x \in X .\right.
$$

Now we claim that Theorem 2 and Corollary 3 in [17] cannot be used to prove the existence of common fixed points of the mappings $S$ and $T$ in $X$, and Theorem 2 in [13], Theorem 2.1 in [1] and Theorems 3.1-3.3 in [9] are useless in proving the existence of fixed points of the mapping $S$ in $X$.

Suppose that there exists $(\varphi, \psi) \in \Phi \times \Psi_{1}$ satisfying the condition of Theorem 2 in [17], that is,

$$
\int_{0}^{d(S x, T y)} \varphi(t) d t \leq \psi\left(\int_{0}^{M(x, y)} \varphi(t) d t\right), \quad \forall x, y \in X
$$

where

$$
M(x, y)=\max \left\{d(x, y), d(x, S x), d(y, T y), \frac{1}{2}[d(y, S x)+d(x, T y)]\right\}
$$

Put $x_{0}=1$ and $y_{0}=\frac{3}{2}$. It follows from (2.15), (2.16) and $(\varphi, \psi) \in \Phi \times \Psi_{1}$ that

$$
\begin{aligned}
M\left(x_{0}, y_{0}\right) & =\max \left\{d\left(x_{0}, y_{0}\right), d\left(x_{0}, S x_{0}\right), d\left(y_{0}, T y_{0}\right), \frac{1}{2}\left[d\left(y_{0}, S x_{0}\right)+d\left(x_{0}, T y_{0}\right)\right]\right\} \\
& =\max \left\{d\left(1, \frac{3}{2}\right), d\left(1, \frac{3}{2}\right), d\left(\frac{3}{2}, 2\right), \frac{1}{2}\left[d\left(\frac{3}{2}, \frac{3}{2}\right)+d(1,2)\right]\right\} \\
& =\frac{1}{2}
\end{aligned}
$$

and

$$
\begin{aligned}
\int_{0}^{\frac{1}{2}} \varphi(t) d t & =\int_{0}^{d\left(S x_{0}, T y_{0}\right)} \varphi(t) d t \leq \psi\left(\int_{0}^{M\left(x_{0}, y_{0}\right)} \varphi(t) d t\right) \\
& =\psi\left(\int_{0}^{\frac{1}{2}} \varphi(t) d t\right)<\int_{0}^{\frac{1}{2}} \varphi(t) d t
\end{aligned}
$$

which is impossible. 
Suppose that there exist $\varphi \in \Phi$ and $k \in[0,1)$ satisfying the condition of Corollary 3 in [17], that is,

$$
\int_{0}^{d(S x, T y)} \varphi(t) d t \leq k \int_{0}^{n(x, y)} \varphi(t) d t \quad \text { for each distinct } x, y \in X,
$$

where

$$
n(x, y)=\max \left\{d(x, y), \frac{d(y, T y)[1+d(x, S x)]}{1+d(x, y)}\right\} .
$$

Take $x_{0}=1$ and $y_{0}=\frac{3}{2}$. It follows from (2.17), (2.18), $k \in[0,1)$ and $\varphi \in \Phi$ that

$$
\begin{aligned}
n\left(x_{0}, y_{0}\right) & =\max \left\{d\left(x_{0}, y_{0}\right), \frac{d\left(y_{0}, T y_{0}\right)\left[1+d\left(x_{0}, S x_{0}\right)\right]}{1+d\left(x_{0}, y_{0}\right)}\right\} \\
& =\max \left\{d\left(1, \frac{3}{2}\right), \frac{d\left(\frac{3}{2}, 2\right)\left[1+d\left(1, \frac{3}{2}\right)\right]}{1+d\left(1, \frac{3}{2}\right)}\right\} \\
& =\frac{1}{2}
\end{aligned}
$$

and

$$
\begin{aligned}
\int_{0}^{\frac{1}{2}} \varphi(t) d t & =\int_{0}^{d\left(S x_{0}, T y_{0}\right)} \varphi(t) d t \leq k \int_{0}^{n\left(x_{0}, y_{0}\right)} \varphi(t) d t \\
& =k \int_{0}^{\frac{1}{2}} \varphi(t) d t<\int_{0}^{\frac{1}{2}} \varphi(t) d t
\end{aligned}
$$

which is a contradiction.

Suppose that there exist $\varphi \in \Phi$ and $k \in[0,1)$ satisfying the condition of Theorem 2 in [13], that is,

$$
\int_{0}^{d(S x, S y)} \varphi(t) d t \leq k \int_{0}^{m(x, y)} \varphi(t) d t, \quad \forall x, y \in X,
$$

where

$$
m(x, y)=\max \left\{d(x, y), d(x, S x), d(y, S y), \frac{1}{2}[d(y, S x)+d(x, S y)]\right\} .
$$

Put $x_{0}=1$ and $y_{0}=\frac{3}{2}$. It follows from (2.19), (2.20), $k \in[0,1)$ and $\varphi \in \Phi$ that

$$
\begin{aligned}
m\left(x_{0}, y_{0}\right) & =\max \left\{d\left(x_{0}, y_{0}\right), d\left(x_{0}, S x_{0}\right), d\left(y_{0}, S y_{0}\right), \frac{1}{2}\left[d\left(y_{0}, S x_{0}\right)+d\left(x_{0}, S y_{0}\right)\right]\right\} \\
& =\max \left\{d\left(1, \frac{3}{2}\right), d(1, S 1), d\left(\frac{3}{2}, S \frac{3}{2}\right), \frac{1}{2}\left[d\left(\frac{3}{2}, S 1\right)+d\left(1, S \frac{3}{2}\right)\right]\right\} \\
& =\max \left\{\frac{1}{2}, \frac{1}{2}, \frac{1}{2}, \frac{1}{2}\right\} \\
& =\frac{1}{2}
\end{aligned}
$$


and

$$
\int_{0}^{\frac{1}{2}} \varphi(t) d t=\int_{0}^{d\left(S x_{0}, S y_{0}\right)} \varphi(t) d t \leq k \int_{0}^{m\left(x_{0}, y_{0}\right)} \varphi(t) d t=k \int_{0}^{\frac{1}{2}} \varphi(t) d t<\int_{0}^{\frac{1}{2}} \varphi(t) d t
$$

which is absurd. Observe that Theorem 2 in [13] generalizes Theorem 2.1 in [1], hence Theorem 2.1 in [1] cannot be used to prove the existence of fixed points of $S$ in $X$.

Suppose that there exists $\varphi \in \Phi$ satisfying the condition of Theorem 3.1 in [9], that is,

$$
\int_{0}^{d(S x, S y)} \varphi(t) d t \leq \alpha(d(x, y)) \int_{0}^{d(x, y)} \varphi(t) d t, \quad \forall x, y \in X
$$

where

$$
\alpha: \mathbb{R}^{+} \rightarrow[0,1) \quad \text { and } \quad \limsup _{s \rightarrow t} \alpha(s)<1, \quad \forall t>0 .
$$

Put $x_{0}=1$ and $y_{0}=\frac{3}{2}$. It follows from (2.21), (2.22) and $\varphi \in \Phi$ that

$$
\begin{aligned}
\int_{0}^{\frac{1}{2}} \varphi(t) d t & =\int_{0}^{d\left(S x_{0}, S y_{0}\right)} \varphi(t) d t \leq \alpha\left(d\left(x_{0}, y_{0}\right)\right) \int_{0}^{d\left(x_{0}, y_{0}\right)} \varphi(t) d t \\
& =\alpha\left(\frac{1}{2}\right) \int_{0}^{\frac{1}{2}} \varphi(t) d t<\int_{0}^{\frac{1}{2}} \varphi(t) d t
\end{aligned}
$$

which is impossible.

Suppose that there exists $\varphi \in \Phi$ satisfying the condition of Theorem 3.2 in [9], that is,

$$
\begin{aligned}
& \int_{0}^{d(S x, S y)} \varphi(t) d t \\
& \quad \leq \alpha(d(x, y)) \int_{0}^{d(x, S x)} \varphi(t) d t+\beta(d(x, y)) \int_{0}^{d(y, S y)} \varphi(t) d t, \quad \forall x, y \in X,
\end{aligned}
$$

where

$$
\begin{aligned}
& \alpha, \beta: \mathbb{R}^{+} \rightarrow[0,1) \text { satisfy that } \alpha(t)+\beta(t)<1, \quad \forall t \in \mathbb{R}^{+}, \\
& \underset{s \rightarrow 0^{+}}{\limsup } \beta(s)<1 \quad \text { and } \quad \limsup _{s \rightarrow t^{+}} \frac{\alpha(s)}{1-\beta(s)}<1, \quad \forall t>0 .
\end{aligned}
$$

Put $x_{0}=1$ and $y_{0}=\frac{3}{2}$. It follows from (2.23), (2.24) and $\varphi \in \Phi$ that

$$
\begin{aligned}
\int_{0}^{\frac{1}{2}} \varphi(t) d t & =\int_{0}^{d\left(S x_{0}, S y_{0}\right)} \varphi(t) d t \\
& \leq \alpha\left(d\left(x_{0}, y_{0}\right)\right) \int_{0}^{d\left(x_{0}, S x_{0}\right)} \varphi(t) d t+\beta\left(d\left(x_{0}, y_{0}\right)\right) \int_{0}^{d\left(y_{0}, S y_{0}\right)} \varphi(t) d t \\
& =\left[\alpha\left(\frac{1}{2}\right)+\beta\left(\frac{1}{2}\right)\right] \int_{0}^{\frac{1}{2}} \varphi(t) d t<\int_{0}^{\frac{1}{2}} \varphi(t) d t
\end{aligned}
$$

which is a contradiction. 
Suppose that there exists $\varphi \in \Phi$ satisfying the condition of Theorem 3.3 in [9], that is,

$$
\int_{0}^{d(S x, S y)} \varphi(t) d t \leq \gamma(d(x, y))\left(\int_{0}^{d(x, S x)} \varphi(t) d t+\int_{0}^{d(y, S y)} \varphi(t) d t\right), \quad \forall x, y \in X
$$

where

$$
\gamma: \mathbb{R}^{+} \rightarrow\left[0, \frac{1}{2}\right) \quad \text { and } \quad \limsup _{s \rightarrow t^{+}} \frac{\gamma(s)}{1-\gamma(s)}<1, \quad \forall t>0
$$

Put $x_{0}=1$ and $y_{0}=\frac{3}{2}$. It follows from (2.25), (2.26) and $\varphi \in \Phi$ that

$$
\begin{aligned}
\int_{0}^{\frac{1}{2}} \varphi(t) d t & =\int_{0}^{d\left(S x_{0}, S y_{0}\right)} \varphi(t) d t \\
& \leq \gamma\left(d\left(x_{0}, y_{0}\right)\right)\left(\int_{0}^{d\left(x_{0}, S x_{0}\right)} \varphi(t) d t+\int_{0}^{d\left(y_{0}, S y_{0}\right)} \varphi(t) d t\right) \\
& =2 \gamma\left(\frac{1}{2}\right) \int_{0}^{\frac{1}{2}} \varphi(t) d t<\int_{0}^{\frac{1}{2}} \varphi(t) d t
\end{aligned}
$$

which is impossible.

Next we prove, by using Theorem 2.2, that the mappings $A, B, S$ and $T$ have a unique common fixed point in $X$, where $A, B: X \rightarrow X$ are defined by

$$
A x=\frac{1}{2} x^{2} \quad \text { and } \quad B x=\frac{1}{4} x^{3}, \quad \forall x \in X .
$$

Define two functions $\psi, \varphi: \mathbb{R}^{+} \rightarrow \mathbb{R}^{+}$by

$$
\varphi(t)=6 t^{5}+3 t^{2}+t, \quad \forall t \in[0,+\infty) \quad \text { and } \quad \psi(t)= \begin{cases}t^{2}, & \forall t \in\left[0, \frac{1}{2}\right] \\ \frac{t}{4+t}, & \forall t \in\left(\frac{1}{2},+\infty\right)\end{cases}
$$

It is easy to see that (C1), (C2) and (C3) hold. Let $x, y \in X$. In order to verify (2.14), we have to consider two possible cases as follows.

Case 1. $x \in X \backslash\{1\}$. It is clear that

$$
\int_{0}^{d(S x, T y)} \varphi(t) d t=0 \leq \psi\left(\int_{0}^{m_{4}(x, y)} \varphi(t) d t\right)
$$

Case 2. $x=1$. Note that $\psi$ is nondecreasing on $\left(\frac{1}{2},+\infty\right)$,

$$
\begin{aligned}
m_{4}(1, y) & =\max \left\{d(A 1, B y), d(A 1, S 1), d(B y, T y), \frac{1}{2}[d(S 1, B y)+d(T y, A 1)]\right\} \\
& =\max \left\{\left|\frac{1}{2}-\frac{y^{3}}{4}\right|,\left|\frac{1}{2}-\frac{3}{2}\right|,\left|\frac{y^{3}}{4}-2\right|, \frac{1}{2}\left(\left|\frac{3}{2}-\frac{y^{3}}{4}\right|+\left|2-\frac{1}{2}\right|\right)\right\} \\
& \geq 1
\end{aligned}
$$


and

$$
\begin{aligned}
\int_{0}^{d(S 1, T y)} \varphi(t) d t & =\int_{0}^{\frac{1}{2}}\left(6 t^{5}+3 t^{2}+t\right) d t=\frac{17}{64} \\
& <\frac{5}{13}=\frac{\frac{5}{2}}{4+\frac{5}{2}}=\psi\left(\frac{5}{2}\right) \\
& =\psi\left(\int_{0}^{1}\left(6 t^{5}+3 t^{2}+t\right) d t\right) \\
& \leq \psi\left(\int_{0}^{m_{4}(1, y)} \varphi(t) d t\right) .
\end{aligned}
$$

Hence (2.14) holds. That is, the conditions of Theorem 2.2 are satisfied. Consequently, Theorem 2.2 implies that $A, B, S$ and $T$ have a unique common fixed point $2 \in X$.

\section{Competing interests}

The authors declare that they have no competing interests.

\section{Authors' contributions}

All authors read and approved the final manuscript.

\section{Author details}

1 Department of Mathematics, Liaoning Normal University, Dalian, Liaoning 116029, People's Republic of China.

2Department of Mathematics and RINS, Gyeongsang National University, Jinju, 660-701, Korea. ${ }^{3}$ Department of Applied Mathematics, Changwon National University, Changwon, 641-773, Korea.

\section{Acknowledgements}

This research was supported by the Science Research Foundation of Educational Department of Liaoning Province (L2012380) and Basic Science Research Program through the National Research Foundation of Korea (NRF) funded by the Ministry of Science, ICT \& Future Planning (2013R1A1A2057665).

\section{Received: 7 March 2014 Accepted: 21 May 2014 Published: 02 Jun 2014}

\section{References}

1. Branciari, A: A fixed point theorem for mappings satisfying a general contractive condition of integral type. Int. J. Math. Math. Sci. 29(9), 531-536 (2002). doi:10.1155/S0161171202007524

2. Aliouche, $A$ : A common fixed point theorem for weakly compatible mappings in symmetric spaces satisfying a contractive condition of integral type. J. Math. Anal. Appl. 322(2), 796-802 (2006). doi:10.1016/j.jmaa.2005.09.068

3. Altun, I, Türkoğlu, D: Some fixed point theorems for weakly compatible mappings satisfying an implicit relation. Taiwan. J. Math. 13(4), 1291-1304 (2009)

4. Altun, I, Türkoǧlu, D, Rhoades, BE: Fixed points of weakly compatible maps satisfying a general contractive of integral type. Fixed Point Theory Appl. 2007, Article ID 17301 (2007). doi:10.1155/2007/17301

5. Beygmohammadi, M, Razani, A: Two fixed-point theorems for mappings satisfying a general contractive condition of integral type in the modular space. Int. J. Math. Math. Sci. 2010, Article ID 317107 (2010). doi:10.1155/2010/317107

6. Djoudi, A, Aliouche, A: Common fixed point theorems of Greguš type for weakly compatible mappings satisfying contractive conditions of integral type. J. Math. Anal. Appl. 329(1), 31-45 (2007). doi:10.1016/j.jmaa.2006.06.037

7. Djoudi, A, Merghadi, F: Common fixed point theorems for maps under a contractive condition of integral type. J. Math. Anal. Appl. 341(2), 953-960 (2008). doi:10.1016/j.jmaa.2007.10.064

8. Jachymski, J: Remarks on contractive conditions of integral type. Nonlinear Anal. 71(3-4), 1073-1081 (2009). doi:10.1016/j.na.2008.11.046

9. Liu, Z, Li, X, Kang, SM, Cho, SY: Fixed point theorems for mappings satisfying contractive conditions of integral type and applications. Fixed Point Theory Appl. 2011, Article ID 64 (2011). doi:10.1186/1687-1812-2011-64

10. Liu, Z, Li, ZL, Kang, SM: Fixed point theorems of contractive mappings of integral type. Fixed Point Theory Appl. 2013 Article ID 300 (2013). doi:10.1186/1687-1812-2013-300

11. Liu, Z, Lu, Y, Kang, SM: Fixed point theorems for mappings satisfying contractive conditions of integral type. Fixed Point Theory Appl. 2013, Article ID 267 (2013). doi:10.1186/1687-1812-2013-267

12. Mongkolkeha, C, Kumam, P: Fixed point and common fixed point theorems for generalized weak contraction mappings of integral type in modular spaces. Int. J. Math. Math. Sci. 2011, Article ID 705943 (2011). doi:10.1155/2011/705943

13. Rhoades, BE: Two fixed-point theorems for mappings satisfying a general contractive condition of integral type. Int. J. Math. Math. Sci. 2003(63), 4007-4013 (2003). doi:10.1155/S0161171203208024

14. Sintunavarat, W, Kumam, P: Gregus-type common fixed point theorems for tangential multivalued mappings of integral type in metric spaces. Int. J. Math. Math. Sci. 2011, Article ID 923458 (2011). doi:10.1155/2011/923458 
15. Sintunavarat, W, Kumam, $P$ : Gregus type fixed points for a tangential multi-valued mappings satisfying contractive conditions of integral type. J. Inequal. Appl. 2011, Article ID 3 (2011). doi:10.1186/1029-242X-2011-3

16. Vetro, C: On Branciariś theorem for weakly compatible mappings. Appl. Math. Lett. 23(6), 700-705 (2010) doi:10.1016/j.na.2008.11.046

17. Vijayaraju, P, Rhoades, BE, Mohanraj, R: A fixed point theorem for a pair of maps satisfying a general contractive condition of integral type. Int. J. Math. Math. Sci. 2005(15), 2359-2364 (2005). doi:10.1155/IJMMS.2005.2359

10.1186/1687-1812-2014-132

Cite this article as: Liu et al.: Common fixed point theorems for weakly compatible mappings satisfying contractive conditions of integral type. Fixed Point Theory and Applications 2014, 2014:132

Submit your manuscript to a SpringerOpen ${ }^{\odot}$ journal and benefit from:

- Convenient online submission

- Rigorous peer review

Immediate publication on acceptance

- Open access: articles freely available online

- High visibility within the field

- Retaining the copyright to your article

Submit your next manuscript at $>$ springeropen.com 